\title{
4. How do officials report? Internal and external whistleblowing
}

\author{
Marika Donkin, Rodney Smith and A. J. Brown
}

\section{Introduction}

How often do public officials blow the whistle on wrongdoing internally and how often do they do it externally? Having decided to report, what influences their decisions about to whom and how they should make their disclosure and who else they should go to if they need to take the matter further?

These questions are important for further understanding the nature and significance of current whistleblowing and identifying the types of organisational decisions that might influence the reporting behaviour of employees. As discussed in Chapter 2, organisations tend to respond more negatively to whistleblowing if they are equipped only to react to the relatively rare cases in which whistleblowing occurs publicly. The previous two chapters have shown that when internal and regulatory whistleblowing are considered, the reporting of public interest wrongdoing by officials is a frequent and relatively routine part of organisational life, with almost any official likely to do so depending on the wrongdoing they observe and the organisational context in which they find themselves.

Do these assessments hold for all types of whistleblowing - in particular, for those who blow the whistle externally as well as those whose reporting is only internal? What implications do current reporting patterns have for how organisations need to manage whistleblowing, especially given the evidence in Chapter 3 that trust in management's response to a report of wrongdoing is usually pivotal to whether public officials will blow the whistle at all?

The first part of this chapter gives an overview of the different reporting paths that whistleblowing currently follows in the organisations that participated in this research. In further contrast with a widely held stereotype, the bulk of whistleblowing recorded by the employee survey started (97 per cent) and ended (90 per cent) as an internal process. Only an extremely small proportion (less than 1 per cent) of whistleblowers went outside official channels to the media at any stage; and typically this was a last resort. While this is based on survey data that do not include former employees, the proportion is unlikely to increase significantly. A slightly larger proportion blew the whistle to external watchdog agencies, but again the overall proportion was small (less than 4 per cent at any stage). In the overwhelming majority of cases, officials confronted with wrongdoing blew the whistle internally in the first instance. Moreover, they 
did so mostly up the management chain (84 per cent) rather than through special internal units or processes (less than 10 per cent).

This result has many implications for how whistleblowing is managed and for procedural and legislative systems intended to encourage and govern public interest disclosures. It also demonstrates that reporting paths can be complex, with mixed internal and external dimensions, all of which are important for organisations to recognise in the way in which their reporting procedures are devised.

The second part of the chapter examines whether there are significant differences between those public officials who blow the whistle internally and those who do so externally, in terms of key measures of $\mathrm{OCB}$, an organisationally functional form of pro-social behaviour introduced in Chapter 1. In Chapter 3, it was seen that those who reported wrongdoing did not differ significantly from other employees on any of the four relevant measures of OCB. This chapter continues that analysis by examining what differences - on measures such as initiative or loyalty - exist between those who blow the whistle internally and those who do so externally. On the whole, internal and external whistleblowers gave indications of high levels of OCB, further challenging the stereotype of an external whistleblower as a disgruntled, organisationally unhappy employee. This analysis provides strong confirmation of the usefulness of understanding whistleblowing as a form of pro-social behaviour, as outlined at the outset of the report. Officials who reported externally at any stage, however, indicated higher levels of initiative and lower levels of loyalty than purely internal whistleblowers. The reason for the second result is not known. Slightly lower loyalty could be a predictor of external reporting, or it could be a result of the conditions that lead an official to report externally. Either way, some lessons begin to emerge for the way that whistleblowing should be managed.

The third part of the chapter further analyses these results in light of the degree of trust in management held by respondents. As already shown in Chapter 3, there was no significant difference in job satisfaction for those who reported wrongdoing and those who did not report; but those who reported were marginally less trusting of the management team. Again, the reason for this is not known (for example, whether slightly lower trust is a predictor or a result of reporting). The question of trust becomes even more central to the question of how employees report. The analysis reveals higher trust in management among those who only ever reported internally, and lower trust among those who reported externally at some stage, including in many cases after having reported internally in the first instance.

The discussion examines the implications for organisational efforts to identify and rectify wrongdoing and to manage the individuals involved. While the pattern of internal reporting has many positive implications, these implications 
also have limits. Employees' trust in management is clearly a key factor influencing the options that employees see for reporting perceived wrongdoing - again, as shown in Chapter 3, this is a more important factor than the individual personalities of employees. This tends to confirm that when organisations can engender a higher level of trust, they should be able to encourage more employees to report internally rather than externally. The crucial importance of trust, in conjunction with the great likelihood that any reporting will occur internally, emphasises the importance of organisations' efforts to devise and implement quality internal disclosure procedures and increases their responsibility to manage reported wrongdoing effectively.

At the same time, the reporting patterns described here pose significant questions for current legislative and procedural arrangements. As will be seen in Chapters 7 and 10, employees frequently have a low awareness of the statutory provisions intended to encourage internal and regulatory disclosures. While it is encouraging that many officials have sufficient trust in their direct management chain to report wrongdoing, the fact that so few officials (less than 10 per cent of public interest whistleblowers) went outside the management chain to use specialist internal whistleblowing procedures suggests either a low awareness of, or low confidence in, those alternative internal avenues. If this is the case, the same is likely to be true of staff awareness and/or confidence in the availability of external regulatory avenues.

The overall picture is that despite recent legislative reforms, current whistleblowing systems rely very heavily indeed on the ability of ordinary managers to recognise and take appropriate action in response to public interest disclosures. Public sector employees who do not see this as a viable path, for reasons such as those set out in Chapter 3, are currently more likely to remain silent about perceived wrongdoing than they are to find an alternative whistleblowing avenue-even an authorised internal one. Moreover, when employees do report externally, this is usually after they have already reported internally. Given the reduced organisational loyalty and trust recorded by external whistleblowers, and further results on outcomes set out in Chapter 5 , it is likely that a whistleblower's decision to use an external, authorised reporting path is often made after problems arise with the organisation's handling of the matter, rather than being identified by whistleblowers as a first option.

These results suggest the need for organisations to place greater effort on training and equipping their managers to handle disclosures appropriately and on educating employees about the availability of different reporting avenues. They also indicate the need for closer coordination between line and integrity agencies to ensure disclosures are managed in the most appropriate way as early as possible, including by direct reference to external agencies, rather than waiting 
for whistleblower dissatisfaction to become the trigger for further, external complaints.

\section{Reporting paths}

Public sector employees who wish to report wrongdoing can do so via a large number of paths. The most basic choice they make is whether to confine their disclosure within their organisation or take it to individuals or bodies outside the agency; and, if they choose the latter, whether to confine the external report to regulatory authorities or make it more public. There is a range of possible recipients of reports within most organisations. These include generalist managers such as the reporter's supervisor, another senior manager and the CEO. Agencies also usually have one or more specialist officials or units to deal with reports, such as human resources units, equity and merit units, ethical standards units, audit or fraud investigation units, internal ombudsmen or other complaints units, counselling units and peer support programs. External recipients of wrongdoing reports potentially include government watchdog and investigation agencies, external anti-corruption hotlines, external counselling services, relevant trade unions, members of parliament and journalists.

Existing overseas studies show a number of factors impact on the decision to whistleblow externally as opposed to internally, including management support, awareness and communication about wrongdoing and the climate for retaliation (Dworkin and Baucus 1998; Miceli et al. 1991). Studies have also demonstrated that it is rarely a direct choice of 'either/or' - most external whistleblowers have tried first to report wrongdoing internally, but without success, and tend to view going outside the organisation as a 'last resort' (Rothschild and Miethe 1999). Research on these questions in Australia has been limited and has tended to suggest a different trend. For example, Zipparo (1999b) found that one-third of NSW public sector respondents expressed a preference for reporting corruption externally in the first instance, rather than to anyone within their own organisation.

Public debate about the management of whistleblowing has been dominated by the treatment of officials whose disclosures have appeared in the media (see Brown 2007; Chapter 11, this volume). This debate has given the impression that external whistleblowing is relatively frequent and that the management response to whistleblowers is likely to be negative, when in fact the frequency of external reporting and the full pattern of management responses to whistleblowers have been unknown.

In the present research, evidence about the reporting paths used by whistleblowers was gathered through the employee survey (conducted across 118 agencies) and the internal witness survey (conducted across 15 agencies). The results presented in this section are for those respondents defined in the 
preceding chapters as whistleblowers (that is, 'non-role' reporters who observed and reported 'public interest' matters, and not respondents who observed and/or reported only personnel and workplace grievances).

The employee survey and internal witness survey used slightly different methods for asking respondents to record the paths they took to report wrongdoing. The employee survey asked respondents to indicate the first category of person to whom they reported wrongdoing with the number ' 1 ', the second person (if any) with the number ' 2 ', and so on. The internal witness survey allowed respondents to circle as many categories of person as they liked to whom they had reported wrongdoing 'in the first instance', as well as to then circle all the categories of person to whom they had provided information in any subsequent reports. These differences mean that the data on the reporting paths of the two samples cannot be compared exactly. The employee survey represents reporting as a series of discrete steps (for example, the respondent first went to their manager, then to the union, then to the CEO, then to a government watchdog agency, and so on). In contrast, the internal witness survey represents reporting as two or more episodes of reporting, each possibly involving more or less simultaneous reporting to more than one category of person (for example, the respondent reported at more or less the same time to their manager and union and later reported to the CEO and a watchdog agency).

The results from both surveys confirm the variety of distinct reporting paths available to whistleblowers. In practice, the whistleblowers surveyed often did approach more than one type of person to report wrongdoing. The employee survey whistleblowers provided information to an average of 1.9 recipients. The internal witness survey whistleblowers approached an average of 4.3 recipients, suggesting that this group included a higher proportion of respondents with complex whistleblowing experiences than their counterparts in the employee survey. Both surveys show that public sector whistleblowing typically involves more than a single report to one individual.

The two surveys tell similar stories about reporting paths. Tables 4.1 and 4.2 set out the types of recipients of reports from employees, in order of the frequency of reporting to each type of recipient. In each table, the first column shows how often a type of recipient was the first person to whom a report was made, while the second column shows how often types of recipients were approached at any stage of whistleblowing. The tables show that the most common recipients of wrongdoing reports are generalist managers (supervisors, senior managers and CEOs) in the direct management chain of the organisation, rather than specialist internal bodies such as ethical standards units. Reports to external bodies occur only in a small minority of cases.

The first people who whistleblowers are likely to approach with their concerns are their supervisors. If whistleblowers follow up their initial report (Table 4.1) 
or simultaneously take their report to someone else (Table 4.2), their most likely course of action will be to approach a senior manager. Beyond these two groups of recipients, the targets of initial reports are spread mostly within organisations between CEOs, human resource, equity and merit and audit and fraud units, and externally between unions and government watchdog agencies. This pattern is clearer among respondents to the internal witness survey (Table 4.2) than among respondents to the employee survey (Table 4.1), perhaps because of the different ways in which the reporting path items were asked in the two surveys, because respondents from the internal witness survey tended to have more complex whistleblowing experiences, or both. The prominence of generalist managers, rather than specialist internal units, as initial recipients of whistleblower reports in both surveys could be partly because of the lack of availability of specialist units in some organisations. ${ }^{1}$

Table 4.1 Recipients of reports from public interest whistleblowers, employee survey

\begin{tabular}{|c|c|c|c|}
\hline Recipient & Initial recipient $(\%)^{\mathrm{a}}$ & Overall recipient $(\%)^{b}$ & $\begin{array}{c}\text { Stage recipient } \\
\text { contacted (average) }^{\circ}\end{array}$ \\
\hline Supervisor & 65.7 & 72.8 & 1.13 \\
\hline Senior manager & 15.0 & 41.1 & 1.76 \\
\hline Peer support officer & 3.5 & 8.5 & 2.13 \\
\hline CEO & 3.4 & 13.1 & 2.27 \\
\hline Human resources/equity and merit unit & 1.8 & 10.5 & 2.55 \\
\hline Union & 1.8 & 8.3 & 2.71 \\
\hline Internal audit/fraud unit & 1.1 & 4.3 & 2.64 \\
\hline Internal ethical standards unit & 1.0 & 3.2 & 3.04 \\
\hline Government watchdog agency & 0.8 & 3.5 & 3.69 \\
\hline Internal ombudsman/ complaints unit & 0.5 & 2.4 & 3.40 \\
\hline External hotline/ counselling service & 0.5 & 1.7 & 5.71 \\
\hline Member of parliament & 0.4 & 1.1 & 5.56 \\
\hline Internal hotline/ counselling service & 0.2 & 1.8 & 4.67 \\
\hline Journalist & 0.1 & 0.7 & 9.17 \\
\hline
\end{tabular}

${ }^{a}$ Respondents were asked to indicate the first person to whom they reported a case of wrongdoing, followed by the second person, if applicable, and so on. Percentages total less than 100 because an 'other' category has been omitted.

${ }^{b}$ Percentages in this column represent the percentage of whistleblowers who reported a case of wrongdoing to each type of recipient at any stage in the reporting process. The percentages in this column total more than 100 because respondents were able to indicate all the people to whom they reported wrongdoing and some reported to more than one.

${ }^{\mathrm{c}}$ Figures indicate the average stage in the reporting process when particular types of report recipients were contacted by whistleblowers. Lower figures indicate contacts early in the process; higher figures indicate later contacts.

Source: Employee survey: Q28 $(\mathrm{n}=835)$. 
The broad patterns of reporting are presented in Figure 4.1 (employee survey) and Figure 4.2 (internal witness survey). The figures simplify the whistleblowing process by reducing the various recipients of reports into three categories: solely internal, solely external and mixed (internal and external). The figures also reduce reporting to two broad stages: the initial report (to one person in Figure 4.1 and to one or more people in Figure 4.2), and then all further reports.

Table 4.2 Recipients of reports from public interest whistleblowers, internal witness survey (per cent)

\begin{tabular}{l|cc}
\hline Recipient & Initial recipient $^{\mathrm{a}}$ & Overall recipient $^{\mathrm{b}}$ \\
\hline Supervisor & 37.5 & 40.3 \\
Senior manager & 36.8 & 45.1 \\
& & \\
Human resources/equity and merit unit & 11.8 & 20.1 \\
CEO & 11.1 & 26.4 \\
Union & 10.4 & 20.1 \\
Internal audit/fraud unit & 10.4 & 22.2 \\
Government watchdog agency & 10.4 & 25.0 \\
Internal ethical standards unit & 5.6 & 16.7 \\
Internal ombudsman/complaints unit & 4.9 & 6.9 \\
Member of parliament & 4.2 & 13.2 \\
Internal hotline/counselling service & 2.8 & 6.3 \\
External hotline/counselling service & 2.8 & 4.2 \\
Peer support officer & 2.1 & 4.9 \\
Journalist & 1.4 & 6.3 \\
\hline
\end{tabular}

${ }^{a}$ Percentages in this column total more than 100 because respondents were able to indicate all the people to whom they reported wrongdoing in their first stage of reporting and some reported to more than one person.

${ }^{\mathrm{b}}$ Percentages in this column represent the percentage of whistleblowers who reported a case of wrongdoing to each type of recipient at any stage in the reporting process. The percentages in this column total more than 100 because respondents were able to indicate all the people to whom they reported wrongdoing and some reported to more than one.

Source: Internal witness survey: Q30 $(\mathrm{n}=144)$. 
Figure 4.1 Reporting paths of public interest whistleblowers, employee survey (per cent)

\section{Initial report}

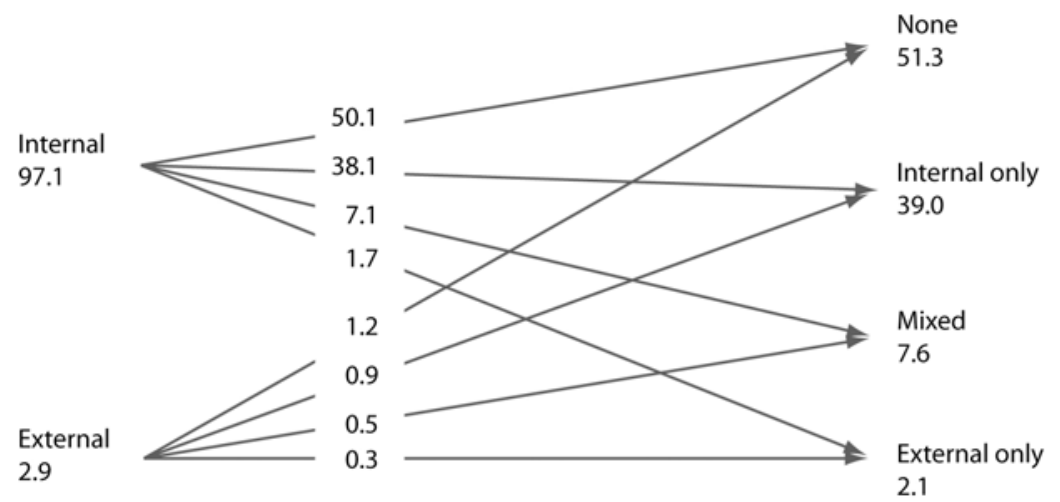

Notes: 'Internal' includes reports to one of the following: supervisors, senior managers, CEOs, internal ethical standards units, internal audit or fraud units, internal ombudsmen or complaints units, human resource or equity and merit units, internal hotlines and counsellors and peer support officers. 'Internal only' includes reports made only to one or more recipients in the 'internal' category. 'External' includes reports to one of the following: external hotlines or counselling services, unions, government watchdog agencies, members of parliament or journalists. 'External only' includes reports made only to one or more recipients in the 'external' category. 'Mixed' includes reports made to 'internal' and 'external' recipients. Source: Employee survey: Q28 (n = 858).

In the first instance, almost all reporting ( 97 per cent in the employee survey and 80 per cent in the internal witness survey) is directed solely at internal recipients. Less than one-tenth of whistleblowers in either survey took their first report exclusively to someone outside their organisation. The reporting path taken by whistleblowers almost always begins within the organisation for which they work.

The second stage in Figures 4.1 and 4.2 concerns what happens next. Two-fifths to one-half of whistleblowers do not pursue their reporting beyond the initial stage. Their reports are resolved in one way or another, or else they let the matter drop. There is some movement towards involving external bodies and individuals in subsequent reporting. Nonetheless, external reporting remains a minority practice. Between one-half (internal witness survey) and four-fifths of whistleblowers who make subsequent reports keep them completely in-house. Only between 11.5 per cent (employee survey) and 37.7 per cent (internal witness survey) of whistleblowers ever take reports of wrongdoing outside their organisations at any time during their reporting. 
Figure 4.2 Reporting paths of public interest whistleblowers, internal witness survey (per cent)

Initial report

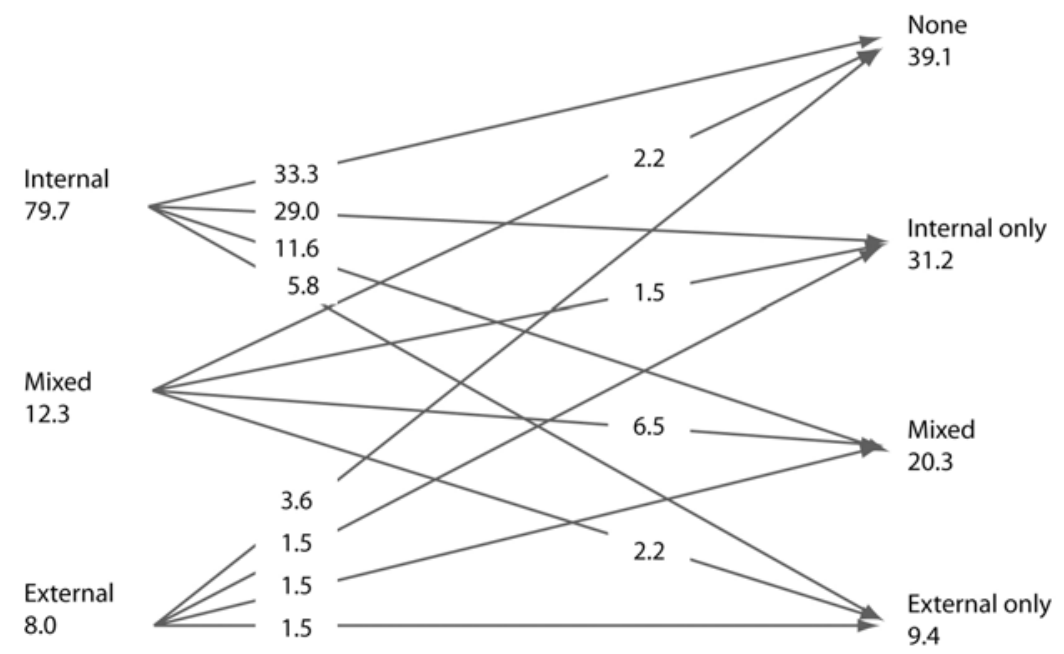

Source: Internal witness survey: Q30, Q38 $(n=138)$.

Even with the simplifications inherent in Figures 4.1 and 4.2, the broad patterns of reporting are complex. Also, when whistleblowers pursue their reporting beyond a first stage - and, as we see, only about half seem to do so- the recipients of their reports become more diverse, as they cast around for someone to deal with the wrongdoing they believe has occurred. As is shown in Tables 4.1 and 4.2, specialist units become more prominent, as do unions and government watchdog agencies (at least in Table 4.2). Even so, none of these bodies overtakes supervisors or managers in the volume of reports they receive. Even among the internal witness survey respondents, who showed stronger tendencies than their counterparts in the employee survey to spread their concerns widely, 30 per cent of whistleblower reports were dealt with exclusively by generalist managers.

What are the implications of these reporting patterns? At least four points can be made. First, public discussion of whistleblowing in Australia is almost certainly distorted by the relatively small number of cases that are eventually taken to journalists and members of parliament. Table 4.1 suggests that less than 2 per cent of whistleblower reports are ever received by journalists and parliamentarians, and they are almost never the first recipients. Within this total, less than 1 per cent of initial reports are made to the media. Indeed, the third column in Table 4.1 shows that, on average, parliamentarians are the fifth recipients of whistleblower reports and journalists are the ninth. As noted in 
Chapters 1 and 2, the data captured by the employee survey do not provide a total picture of all whistleblowing, since the survey respondents did not include whistleblowers who had since left the organisation-a higher proportion of whom might be reasonably assumed to have pursued their grievance externally (and even been suspended or sacked as a result). Some indication of the extent to which this might change the overall picture is given by the more complex cases captured by Table 4.2, which are less representative of the public sector as a whole but in which the respondents are likely to have more diverse reporting paths (see also Figure 4.2). This evidence shows higher but still comparatively low rates of whistleblower contact with journalists and parliamentarians.

From this, it is clear that journalists and parliamentarians see only the tip of the whistleblowing iceberg, and are also more likely to encounter cases of whistleblowing that are already complicated, if not rancorous. While this more public whistleblowing may well be justified, on occasion, by the failure of organisations to address alleged wrongdoing in the first instance, the greater extent of internal whistleblowing does not automatically mean that wrongdoing is simply swept under the carpet (see Chapter 5).

Second, this confirms that in the majority of whistleblowing cases, public sector managers have the opportunity to deal with wrongdoing themselves. They get first opportunity to resolve the problem. It is almost always only after wrongdoing has been brought to management attention that whistleblowers look elsewhere for solutions. This suggests that effective public sector procedures for dealing with whistleblowing should be focused on anyone who has a supervisory role. The pattern appears so strong that procedures stipulating that only certain officers in the organisation can receive disclosures, perhaps removed from the immediate workplace of many employees, are unlikely to shake the frequency of this behaviour. In some instances, the solution could lie in training supervisors to act as effective 'post boxes' for the effective referral of disclosures to more appropriate locations in (or outside) the organisation. Strategies that rely only on designated people other than supervisors to receive disclosures are not, however, likely to prove effective for the management of reports, especially if they also reduce the extent to which supervisors feel able or willing to take responsibility for those concerns of which they become aware.

Third, the current heavy reliance on supervisors and line managers as the first points of disclosure could involve some risk that disclosures are first made to supervisors and line managers in circumstances in which they are not the best person to first receive the information. In some cases, the fact that a whistleblower elected to instead report first to a specialist internal unit, or to an external watchdog agency, could reflect a conscious decision by an employee that they were not prepared to trust line management with the disclosure. This could be due to the specific nature of the perceived wrongdoing or the people involved, 
including supervisors themselves. As shown in Chapter 3, however, and discussed further below, whistleblowers were not shown by the employee survey to be particularly untrusting of management on the whole. The strength of the reliance on supervisors and line managers therefore makes it likely that in at least some instances, staff could be blowing the whistle in an entirely trusting manner, without knowing or considering the full history (for example, when a problem has been going on for some time because a supervisor has previously failed to act). This likelihood also has implications for agencies' reporting procedures, including decisions about how the process is best managed once the whistle is blown.

Fourth, the motivations behind the strong tendency of whistleblowers to internally report to generalist managers need to be understood. Do whistleblowers report internally to generalist managers because they see this as the right thing to do, as part of being good organisational citizens? Does this reflect their first preference, or are they limited in their organisational choices? Given that many statutory regimes provide for multiple reporting avenues and given that most of the agencies surveyed have a range of internal reporting avenues including specialist units, what does the relatively low use of those avenues say about current whistleblowing policies? Finally, are those whistleblowers who go external necessarily less loyal or more disgruntled than those who remain internal? The remainder of this chapter takes up these questions.

\section{When do whistleblowers choose internal or external paths? Organisational citizenship behaviour}

As seen in Figures 4.1 and 4.2, the majority of officials blow the whistle internally in the first instance; and, for the majority, the matter also remains internal throughout. Further questions arise from this pattern: what does it indicate about the character of whistleblowing? Do people prefer to blow the whistle internally because that is simply their instinctive reaction? Or is there evidence that they are blowing the whistle internally because of a sense of duty and loyalty to the organisation? Is the decision to go outside the organisation associated positively with any evidence of an increased tendency to disloyalty? What are the implications for management?

The analysis of who reported wrongdoing provided in Chapter 3 already provides a broad backdrop to these questions. On the whole, the employee survey provided little evidence consistent with a stereotype of whistleblowers as generally disgruntled or embittered employees. This was established by comparing the levels of OCB shown by respondents, between non-role reporters (whistleblowers), role reporters and those respondents who observed wrongdoing but who did not report it (non-reporters). Whistleblowers showed higher levels of 'interpersonal helping' and 'individual initiative' (sub-scales of OCB) behaviour 
than non-reporters, but did not differ from non-reporters on either the 'personal industry' or 'loyal boosterism' sub-scales used to measure levels of OCB.

OCB is a constellation of discretionary extra-role behaviours enacted by individual employees that benefit the organisation and its members (Graham 1989; Organ 1988:4; Penner et al. 2005). While many whistleblowers have their own motivations for reporting wrongdoing, the fact that they score either higher or the same as non-reporters on these behavioural scales, combined with the objectively beneficial effects of a good deal of this reporting, justifies the characterisation of whistleblowing as pro-social behaviour (Dozier and Miceli 1985; Miceli et al. 2001; Miceli and Near 2006; Chapter 1, this volume).

Whistleblowers' choices about whether to report internally or externally provide a further departure point for analysing the extent to which whistleblowing is best understood as pro-social, in an organisational context. This is because, while much internal whistleblowing might easily be imagined to be beneficial to the organisation, external whistleblowing immediately raises a range of broader challenges. Even though pro-social behaviour is by definition 'generally beneficial' to society, it can also at times be organisationally dysfunctional (Brief and Motowidlo 1986; Moorman and Blakely 1995). Nowhere is this better demonstrated than by the issue of external whistleblowing, which is generally recognised as good for society (at least when vindicated), but which can involve intense conflict between an organisation and its members and throw substantial parts of its management into turmoil, even if the organisation ends up better off.

By further examining levels of OCB among those who report internally versus those who report externally, we can therefore test whether the characterisation of whistleblowing as pro-social still holds at an organisational level, as well as a broader social level. For obvious reasons, pro-social behaviour and OCB have long been seen as related concepts (Brief and Motowidlo 1986; Podsakoff et al. 2000; Puffer 1987, cited in Williams and Anderson 1991). The match is, however, not necessarily perfect, because OCB is intended to describe behaviours that are inherently organisationally functional. In the present study, if whistleblowing is shown to also be organisationally functional through $\mathrm{OCB}$, its character as pro-social will only be strengthened.

More specifically, two of the four OCB sub-scales used in the employee survey ${ }^{2}$ provide measures of attitudes that are directly relevant to decisions to blow the whistle externally or internally. 'Individual initiative' provides a measure of willingness to communicate and attempt to influence others in the workplace, including behaviour that could be seen as 'rocking the boat' (Graham 1989:9; cf. Podsakoff et al. 2000). For example, one item asks respondents to indicate their agreement with the statement: 'For issues that may have serious consequences, I express opinions honestly, even when others disagree.' As noted 
above, whistleblowers generally showed higher levels of 'individual initiative' attitudes than non-reporters. 'Loyal boosterism' is also directly relevant, but for the reverse reason - since it is usually presumed to indicate a preference for keeping issues internal. These items are used to measure respondents' attitudes to promoting, protecting and defending the organisation under adverse conditions (Podsakoff et al. 2000) - for example: 'I defend the organisation when other employees criticise it.' As noted above, whistleblowers generally showed the same levels of 'loyal boosterism' as non-reporters. The question arises, however, whether this holds true for external whistleblowers compared with internal ones, given that going outside the management chain or outside the organisation is often viewed as disloyal - especially by anyone likely to be unexpectedly exposed or embarrassed as a result. Disloyalty could be associated with normal loyalty that has been compromised by selfish motives (Weinstein 1979) or simply having been sacrificed for the higher ethical principle of reporting the wrongdoing (Jubb 1999). In either case, many organisational responses reflect assessments about the degree of loyalty or disloyalty that should attach to someone who makes an external report.

In theory, the pro-sociality of whistleblowing and levels of organisational citizenship should be stronger for those who report internally compared with those who do so externally (Dozier and Miceli 1985). Internal whistleblowing is more likely to facilitate early detection of wrongdoing and create an opportunity for timely investigation and corrective action (Berry 2004). Even though the motivation (to help put a stop to wrongdoing) and process (notifying people who have the power to do something about it) might be the same, it is, however, reasonably apparent to the whistleblower that the repercussions for the organisation are likely to be more extreme if outside organisations are involved. Further, some types of external whistleblowing are more likely to be antisocial than pro-social, such as reporting to the media to gain an individual advantage without first raising concerns internally (Miceli et al. 2001; Miceli and Near 2006).

The reasoning outlined above suggests four hypotheses. ${ }^{3}$

H1. OCB should be more strongly positively related to a preference for initial internal whistleblowing, and less strongly related to a preference for initial external whistleblowing.

$\mathrm{H} 2$. OCB should be more strongly positively related to internal reporting as an initial real reporting path, and less strongly related to external reporting as initial real reporting path.

H3. OCB will also be more strongly positively related to real reporting that remains internal only, and less strongly related to any real reporting that includes external reporting (for example, including reports that were initially internal, but subsequently became external). 
H4. As for Hypothesis 3, but comparing only 'non-role' reporters (that is, potential whistleblowers as explained in Chapter 2), since role reporters might be presumed to be more likely to remain internal and also to have higher levels of OCB.

\section{Hypothesis 1: OCB more strongly positively related to preference for initial internal whistleblowing than preference for initial external whistleblowing}

This hypothesis involved examining the stated preferences of respondents to scale items about internal and external reporting in the employee survey, irrespective of whether they reported. Although this chapter is otherwise concerned with officials' real reporting behaviour, this hypothesis allows us to test the attitudes of all 7663 respondents to the survey. As outlined in Chapter 3, the employee survey (Q15) measured 'whistleblowing propensity' as well as real behaviour, including two items that asked respondents to indicate whether they would be 'most likely' to report wrongdoing internally to a supervisor, manager or similar 'in the first instance', or to make their first report externally, to a watchdog body, the media or similar 'in the first instance' (Q15f and 15g). ${ }^{4}$ These items were adapted from those used by Zipparo (1999b).

The hypothesis was tested using a method described by Steiger (1980), which allows a comparison to be made of the correlations of the internal and external reporting variables with the four dimensions of $\mathrm{OCB}$, including the 'individual initiative' and 'loyal boosterism' sub-scales noted as important above.

The hypothesis was supported by the analysis. It was found that all OCB dimensions were significantly more highly correlated with the expressed preference for internal rather than for external reporting. All dimensions were significantly positively related to internal reporting. They were also negatively related to external reporting, with 'interpersonal helping' and 'loyal boosterism' significant in this equation. Significance tests were conducted for all hypotheses and are available for all those that were supported, including this one.

Table 4.3 sets out the correlations and whether they are positive or negative. Note that the 'trust' variable included in Tables 4.3 and 4.4 will be discussed in the next section.

This analysis is especially significant because it suggests that the tendency for public employees to report wrongdoing internally to management might not simply be a product of organisational constraints. For example, while that strong tendency might reflect respondents' lack of knowledge about or confidence in other reporting avenues, it is also consistent with an active preference to report internally - that is, to be able to disclose wrongdoing and have it addressed in ways that remain loyal and rock the boat the least. 
This result is therefore also consistent with the fact that, while it could be necessary and desirable in some cases, external reporting is more likely to be damaging to an organisation and more difficult to manage for whistleblowers and organisations alike (Berry 2004). These difficulties flow from the simple fact that the repercussions for the organisation are likely to be more extreme if outside organisations are involved, before the organisation has an opportunity to respond (Dozier and Miceli 1985). It stands to reason that many employees would be broadly aware of this and would see internal reporting as more viable specifically because it could help to avoid negative publicity and allow problems to be dealt with internally. It might also seem that the welfare of the whistleblower could be managed better, as discussed in later chapters.

In fact, as many legislative and procedural arrangements make clear, internal reporting is not always the best way for wrongdoing to be addressed. In some circumstances, it would be better for the whistle to be blown first to an external regulatory agency. What this analysis shows, however, is that it is unwise to assume that other reporting avenues - even if their use should be promoted — will ever substitute entirely for internal reporting processes, as these are highly likely to remain the first port of call for large numbers of staff.

\section{Hypothesis 2: OCB more strongly positively related to internal reporting as real initial path than external reporting as real initial path}

This hypothesis was tested by using a one-way ANOVA to examine the relationship between the OCB dimensions and the behaviour of all employee survey respondents who said they had reported wrongdoing. This analysis includes all types of real reporting - that is, it is not confined to whistleblowing.

As outlined earlier in the chapter, respondents were asked about their real reporting path, by indicating in what order they reported to different types of people internal and external to the organisation (Table 4.1). The main paths available were: 1) reporting internally initially and remaining internal (or reporting only once, which was an internal report); 2) reporting internally initially and then reporting externally; or 3) reporting externally initially and remaining external (or reporting only once, which was externally). Those who indicated that their first report was internal were divided into one group $(\mathrm{Q} 28 \mathrm{a}-\mathrm{h}$, j) and compared with those who indicated that their first report was external (Q28i, k-n). Whether or not they made any subsequent reports, either internally or externally, was irrelevant to this analysis. For the reasons indicated earlier, there was an imbalance in the relative sizes of these groups of respondents. The number who reported internally initially was very large $(\mathrm{n}=1935,90$ per cent of all reporters), while the number who reported externally initially was very small ( $\mathrm{n}=80,3.7$ per cent of all reporters). Since these variables are so highly skewed, interpretations of the findings can only be undertaken with caution. 
Whistleblowing in the Australian Public Sector

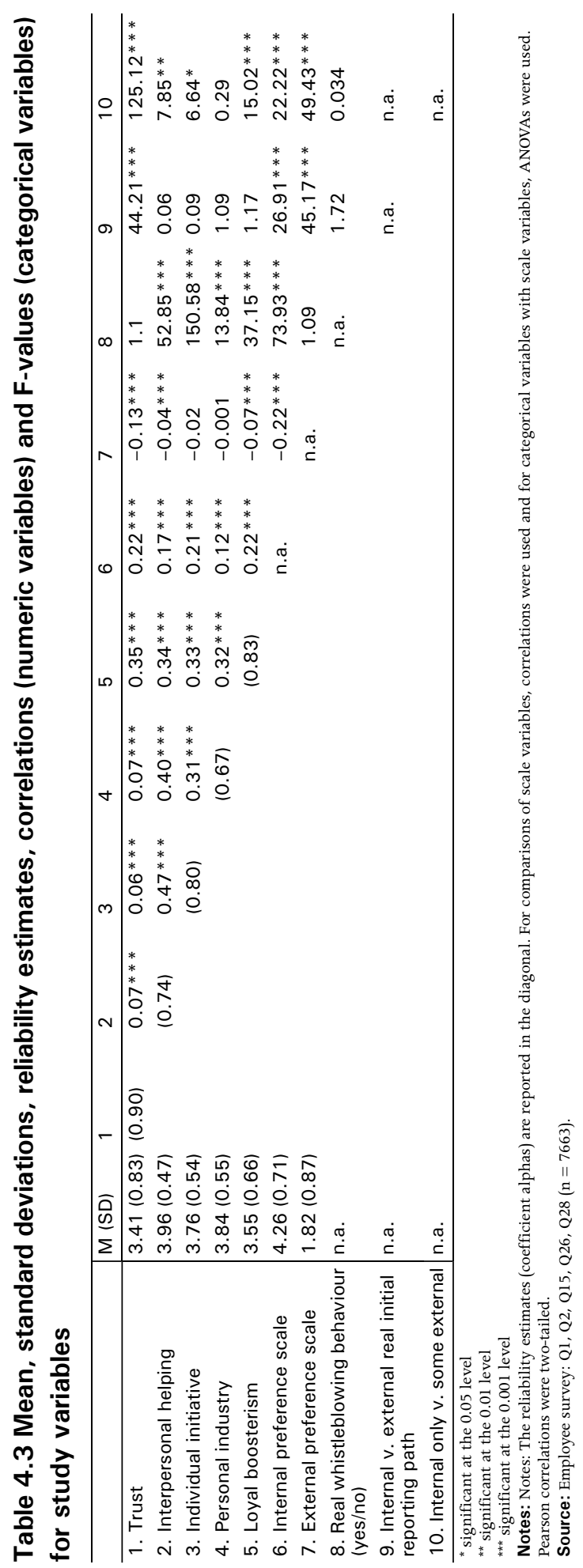


In fact, the hypothesis was not supported. There were no significant differences between the mean scores on any of the OCB sub-scales for those whistleblowers who initially chose an internal reporting path and those who initially chose an external reporting path. Table 4.4 sets out the relevant mean. The importance of this finding is discussed below.

Table 4.4 Comparison of OCB and trust in management (mean) by different reporting paths (all reporters)

\begin{tabular}{lccccc}
\hline Variables & $\begin{array}{c}\text { Interpersonal } \\
\text { helping }\end{array}$ & $\begin{array}{c}\text { Individual } \\
\text { initiative }\end{array}$ & $\begin{array}{c}\text { Mean } \\
\text { Personal } \\
\text { industry }\end{array}$ & $\begin{array}{c}\text { Loyal } \\
\text { boosterism }\end{array}$ & Trust \\
\hline $\begin{array}{l}\text { Internal whistleblowing as initial } \\
\text { reporting path }\end{array}$ & 4.02 & 3.90 & 3.86 & 3.59 & 3.30 \\
$\begin{array}{l}\text { External whistleblowing as initial } \\
\text { reporting path }\end{array}$ & 4.03 & 3.91 & 3.79 & 3.50 & 2.62 \\
\hline $\begin{array}{l}\text { Internal reporting only } \\
\text { Some external reporting }\end{array}$ & 4.01 & 3.88 & 3.85 & 3.61 & 3.36 \\
\hline
\end{tabular}

Source: Employee survey: Q28 $(\mathrm{n}=2015)$.

\section{Hypothesis 3: OCB will be more strongly related to real reporting that remains internal only and less strongly related to reporting that includes external reporting}

This hypothesis compared those respondents in the employee survey who only ever reported internally ( $\mathrm{n}=1728,81$ per cent of all reporters) with those who reported externally at any point, including those who reported internally initially but subsequently reported externally ( $\mathrm{n}=324,15$ per cent of all reporters). Note that these percentages total less than 100 per cent due to missing data. Again, this analysis includes all types of real reporting and is not confined to whistleblowing. The hypothesis was tested using a one-way ANOVA. These mean figures are also shown in Table 4.4.

Significant differences appeared on three of the OCB sub-scales, going in different directions. Contrary to the hypothesis, those who reported externally at any point had higher scores than internal reporters for 'individual initiative' and, as expected, lower scores for 'loyal boosterism'. Accordingly, compared with those who only ever reported internally, those who reported externally at any point were more similar to the stereotype of being more prepared to rock the boat and having less loyalty, but not at the expense of their overall similarity in organisational citizenship. In particular, 'personal industry' for both groups remained the same and, contrary to what was hypothesised, those who reported externally at any point rated higher than the internal group for interpersonal helping' (see Endnote 5 for the significance tests). 


\section{Hypothesis 4: For 'non-role' reporters, OCB might be more strongly related to real reporting that remains internal only and less strongly related to reporting that includes external reporting}

This hypothesis was based on the previous one, but was restricted to comparison of the reporting behaviour of non-role reporters. In other words, the analysis was confined to potential whistleblowers who had reported wrongdoing outside their organisational role, but still included those who reported personnel or workplace grievances and was thus not confined to public interest whistleblowers. A total of 1157 non-role reporters only reported internally, compared with 256 non-role reporters who reported externally at some point.

Significantly, once again, a result contrary to the hypothesis was found. Despite narrowing the group towards the definition of whistleblowing used elsewhere in this book, the results did not change from Hypothesis 3. External reporters similarly scored higher for 'individual initiative' (mean includes external = 3.93; mean internal only $=3.82$ ) and 'interpersonal helping' (mean includes external $=4.08$; mean internal only $=4$ ) and lower for 'loyal boosterism' (mean includes external $=3.33$; mean internal only $=3.53$ ), with no difference for 'personal industry' (mean $=3.85)$. See Endnote 5 for significance tests.

Taken together, these results give new insights into how whistleblowing should be viewed by organisations, based on the reporting paths preferred and chosen by employee survey respondents. The fact that higher levels of OCB correlated strongly with those who expressed a preference for reporting internally rather than externally in the first instance suggests that employees could recognise the desirability of internal reporting - for their own sake and that of their organisation. Consistent with some of the broad findings in Chapters 2 and 3, this result indicates that whistleblowing is not only accurately characterised as pro-social, it is seen as pro-social, at least if internal in the first instance.

While the preference for internal whistleblowing confirms its underlying pro-sociality, a different picture emerges in terms of the relationship between measures of $\mathrm{OCB}$ and real reporting behaviour. Here, the analyses were not confined to public interest whistleblowing, but the fact that all types of wrongdoing were included (including personnel and workplace grievances) makes the results even more significant. The internal and external initial reporting path groups demonstrated no differences in their OCB scores. This indicates that, contrary to the preference, even those who report externally in the first instance retain (on average) their positive view of their role and relationship with their organisation. The result must, however, be treated with caution given the small size of the latter group.

In response to Hypothesis 3, the comparison of two more balanced groups - those who only ever reported internally and those who reported externally at any 
point - suggests the picture is more complex. Some of the outcomes stand to reason. Employees who blew the whistle externally at some point were more likely to rate highly for 'individual initiative' (including 'rocking the boat'). They also tended to rate lower for 'loyal boosterism' (loyalty to and promoting the organisation), but here, as in Chapter 3, the direction of cause and effect is not clear. Given the strength of the preference for internal reporting shown above, it appears more likely that this drop in loyalty is owed to the respondents' perception of the response once the report is made internally rather than that those who report externally are necessarily always predisposed to be less loyal. This is consistent with the evidence that very few employees blow the whistle externally without first having blown it inside the organisation. Accordingly, the external reporters' higher scores for 'initiative' and lower scores for 'loyalty' could simply reflect their experience of having felt compelled to pursue the matter externally, against what would have been their normal preference, rather than the other way around.

Most importantly, the fact that external reporters also rated higher for 'interpersonal helping' and equivalently for 'personal industry' means that, overall, their characterisation as organisational citizens holds, as does the characterisation of reporting - even when external - as pro-social. In Hypothesis 4 , these results also held when the analysis was narrowed from all reporters to simply non-role reporters. Even with personnel and workplace grievances still included, therefore, we have results consistent with those in Chapter 3. There is little evidence that those who report wrongdoing externally are any more likely to be disgruntled or organisationally unhappy employees than those who report internally, except perhaps as a result of what happens when they first make an internal report. Just as the nature of the perceived wrongdoing and organisational context appear to have more to do with who blows the whistle than individual attitudes, it appears to be factors other than the individual that explain how and to whom employees choose to make any report.

\section{Do whistleblowers' choices vary with trust in management?}

Trust has been defined as 'one party's willingness to be vulnerable to another based on the confidence that the latter party is benevolent, reliable, competent, honest and open' (Tschannen-Moran and Hoy 2000:7). Chapter 3 showed that public employees who reported wrongdoing outside their role had, on average, somewhat lower trust in management and lower expectations of the management response to whistleblowing than those who observed wrongdoing but did not report it. On the one hand, this could indicate that some distrust is conducive to reporting. After all, trust is also consistent with deference to authority and a lack of critical review, while some wariness and suspicion is needed for resilient organisations (Kramer 1999). 
On the other hand, the reasons given in Chapter 3 by those who did and did not report showed that levels of confidence in the management response were a crucial part of their decision about whether or not to report. This suggests that, on average, the employees who reported wrongdoing might have had higher trust in management when they reported and experienced a decline in trust as a result of their experience. As we will see in Chapter 5, even 'successful' whistleblowers commonly say that they felt less trust in their organisation as a result of the experience than they did before. In other words, the most logical explanation appears to be that - while still broadly trusting of the management team in their organisation - a majority of reporters do appear to become slightly less trusting as a result of reporting.

Another way to test this conclusion is through the evidence for reporting paths. This chapter has already shown that the bulk of reporting is internal and that for most staff, for better or worse, this appears to be the natural course of action. It has been hypothesised elsewhere that while the decision to take action in response to observed wrongdoing is dependent on the degree of trust placed in management by staff, this is especially true if the action is internal (Dozier and Miceli 1985; Ashforth and Anand 2003; Miceli and Near 2006). Internal reporting therefore should increase in line with trust, given existing evidence of the positive relationships between trust, pro-social behaviour and OCB (Podsakoff et al. 2000; Thau et al. 2004).

If distrust of management was a predictor of reporting, rather than a result of it, we might expect to see a relatively high level of external reporting. Although we already know that most reporting is instead internal, we can still further test the importance of trust by seeing whether internal reporting appears to increase or decrease in line with trust. Relatively little research has been done internationally on the relationship between trust and whistleblowing, although McLain and Keenan (1999) propose that there could be one. In particular, they believe that when there is conflict between an organisation's formal policies and informal structures and a culture of rationalising and accepting wrongdoing, organisational trust is weakened and faith in internal reporting is lowered. Confirming the relationship between trust and internal reporting will therefore also have implications for whether a good deal of wrongdoing is ever reported at all, given that the next option for most public employees in response to wrongdoing, if they do not report internally, is not the option of reporting externally but rather not reporting at all.

To better assess the relationship between trust and reporting, three further hypotheses were arrived at.

H5. Trust will be positively related to internal whistleblowing preference in the first instance and negatively related to external whistleblowing preference in the first instance. 
H6. Trust will be more strongly positively related to real reporting that remains internal only, and less strongly related to real reporting that includes external reporting.

H7. As for Hypothesis 6, but comparing only 'non-role' reporters (that is, potential whistleblowers such as those discussed earlier in the chapter), since role reporters might be presumed to be more likely to remain internal and also to have higher levels of trust in management.

\section{Hypothesis 5: Trust positively related to preference for initial internal whistleblowing and negatively related to preference for initial external whistleblowing}

Trust in management was measured using Gabarro and Athos's (1976, cited in Robinson and Rousseau 1994) seven-item 'bases of trust' (employee survey: Q1). The items were reworded to read 'management team' to specify who respondents should consider when responding-for example: 'My management team (supervisor/line manager and above) is open and up front with me.' The Steiger (1980) method was again used to test the relationship between the trust results and the reporting preference discussed earlier as an element of whistleblowing propensity in relation to Hypothesis 1 (employee survey: Q15f and g).

The hypothesis was supported. Despite the fact that trust was slightly lower for reporters than non-reporters, it was significantly more highly correlated with the internal than the external reporting variable (Table 4.3). Trust was positively and significantly associated with internal reporting and negatively and significantly associated with external reporting (see Endnote 5 for significance tests).

\section{Hypothesis 6: Trust will be more strongly positively related to real reporting that remains internal only and less strongly related to real reporting that includes external reporting}

This hypothesis was tested using a one-way ANOVA, again comparing the groups identified earlier in relation to Hypothesis 3: those who reported internally initially and never reported externally and those who reported externally at any stage. Again, this analysis includes all types of real reporting and is not confined to whistleblowing.

The hypothesis was supported. Trust was much higher for those who reported internally only than for those reporters who also used external reporting paths (or only external reporting paths), as shown by the mean figures in Table 4.4. Trust showed highly significant differences between the reporting paths (Table 4.5). This tends to confirm the association between having reported and a slightly lower overall level of trust, compared with employees who have not reported. The result is also consistent with a reduction in trust that has occurred as a result 
of the reporting process (having typically been internal first, then external) rather than as a predictor of the initial internal report. In any event, it tends to confirm the overall importance of high trust in management among the initial internal reporters, being also the bulk of people who ever report wrongdoing.

\section{Hypothesis 7: For 'non-role' reporters, trust might be more strongly related to real reporting that remains internal only and less strongly related to reporting that includes external reporting}

This hypothesis was based on the previous one, but, like Hypothesis 4, it was restricted to comparison of the reporting behaviour of non-role reporters. Again, this brought the analysis closer to real whistleblowing, although all types of wrongdoing were still included. Notably, the results did not change, with internal reporters similarly scoring significantly higher on trust (mean $=3.21$ ) than reporters who included external reporting (mean $=2.57$ ). In comparison, role reporters who remained internal and those who included external reporting did not differ in their mean trust in management. Significance tests are reported in Endnote 5.

These results show that respondents who scored higher on the trust scale were more likely to follow the tendency towards internal reporting, as an expression of what they would expect to do hypothetically and as a description of their real behaviour in response to wrongdoing. Non-role reporters were much more likely to keep the information internal within the organisation, even if this meant continuing to report 'up the line', or to different groups or individuals they believed could do something about the issue. Others simply reported once, the most common report being to the supervisor. This supports the research of McLain and Keenan (1999), who find that trust encourages whistleblowing 'procedurally' through internal channels and distrust discourages whistleblowing or makes external reporting more likely. Rationalising of wrongdoing by management or a conflict between formal policies and informal culture can perpetrate mistrust, which impacts negatively on employee reporting of wrongdoing.

From Chapter 3, it will be recalled that there are many variables that seem to impact on the decision to blow the whistle internally, externally, or at all. In the above analyses, statistically significant demographic variables were held constant, but there were other possible variables of interest for which we did not control (see, for example, Near and Miceli 1996; Sims and Keenan 1998). Nonetheless, initiatives that build employees' trust in management should contribute positively to the preparedness of employees to report and to do so internally in a manner over which the organisation has greatest control. These findings have positive implications for organisations, some of which are discussed in the conclusions below. 


\section{Discussion and conclusions}

This chapter has shown that the majority of whistleblowing in the Australian public sector is internal to agencies, with public employees on the whole showing a tendency to report wrongdoing internally, predominantly to their supervisor or up the chain of management, at least before they make any further reports elsewhere, including outside the organisation. This contrasts sharply with stereotypes of whistleblowing based on cases that become prominent in the media, which are unlikely to be typical and instead to be cases that have involved many stages, many parties and many more complexities and conflicts than the bulk of whistleblowing matters. Chapters 5 and 6 will go on to analyse some of the differences in outcomes.

Nevertheless, this chapter has also shown that employees who blow the whistle externally — while statistically less frequent - no better fit the stereotype of the misfit, disgruntled or organisationally unhappy employee than the bulk of employees who report internally. Employees who expressed a hypothetical view that it was better to report wrongdoing internally than externally also indicated higher levels of OCB. In practice, however, there was little overall difference between those who only ever reported internally and those who reported externally at some stage. On some OCB sub-scales, there were understandable differences; overall, however, the OCB rating remained high even for external reporters, and particularly on those sub-scales that demonstrated the pro-social nature of reporting at the organisational level. OCB is positively related to whistleblowing propensity and real reporting behaviour, in some cases in different ways, but generally irrespective of whether an internal or external reporting path is taken.

All these analyses provide concrete evidence that it is accurate to conceive of whistleblowing as being generally pro-social in its nature. As a result, it becomes even clearer that agencies can ill afford procedures or a management culture in which employees who report wrongdoing are seen as destabilising or troublemakers. Instead, it is clear that whistleblowers, or those with a whistleblowing propensity, are predominantly conventional organisational citizens and 'not the disloyal, marginally socialized [people] they are frequently perceived to be' (Somers and Casal 1994:282). Even when public interest whistleblowing is triggered or accompanied by issues in which employees have strong personal interests, therefore, its character as pro-social behaviour should not be forgotten.

The final analyses have also confirmed the importance of public employees' level of trust in management - generally and in terms of anticipated response to wrongdoing if reported. Employees who report internally are likely to have high trust in management. Whether these trusting expectations are always met is less certain: the most logical explanation for the reporters' average slightly lower 
level of trust is that this flows from the way the cases are then handled. These results tend to confirm that were it not for substantial levels of trust in the organisational response, at least in terms of the wrongdoing being stopped or remedied, it is unlikely that current levels of internal reporting would occur.

Through measures that build employee trust, organisations can expect to maximise the amount of wrongdoing that is reported - internally - in a timely fashion, rather than being left to fester or eventually be reported only externally. The crucial importance of trust, in conjunction with the great likelihood that any reporting will occur internally, emphasises the importance of organisations' efforts to devise and implement quality internal disclosure procedures and increases their responsibility to manage reported wrongdoing effectively. The heavy current reliance on internal reporting therefore places considerable responsibility on agencies to respond well in their investigation and remediation of alleged wrongdoing and to ensure unnecessary adverse consequences do not befall those who report. Management is judged by its actions and by the outcomes of those actions. Accordingly, the trust on which effective internal reporting at least partly depends is itself dependent on whether management has a proven capacity to properly manage those involved.

While the pattern of internal reporting has many positive implications, these implications also have limits. This includes significant questions for current legislative and procedural arrangements.

As will be seen in Chapters 7 and 10, employees frequently have a low awareness of the statutory provisions intended to encourage internal and regulatory disclosures. While it is encouraging that many officials have sufficient trust in their direct management chain to report wrongdoing, the fact that so few officials (less than 10 per cent of public interest whistleblowers) go outside the management chain to use specialist internal whistleblowing procedures suggests the absence of, a low awareness of or low confidence in those alternative internal avenues. If this is the case, the same is likely to be true of staff awareness and/or confidence in the availability of external regulatory avenues.

Consequently, even if it is natural for public employees to have a preference to report wrongdoing internally and 'up the line' in the first instance, the fact that this is currently the overwhelming pattern poses two major challenges. First, it could help explain the significant amount of serious wrongdoing observed by employees about which no action is taken. Chapter 2 showed that 29 per cent of all employee survey respondents who observed very or extremely serious wrongdoing neither reported it nor indicated that anyone else had reported it, nor dealt with it in any other way. For almost one-fifth of the agencies for which that analysis could be performed, this inaction rate exceeded 40 per cent. The evidence in Chapter 3 and this chapter combines to suggest that if public officials 
are not prepared to report wrongdoing internally, the bulk will simply stay silent.

The overall picture is that despite recent legislative reforms, current whistleblowing systems rely very heavily indeed on the ability of ordinary managers to recognise and take appropriate action in response to public interest disclosures. Public sector employees who do not see this as viable are currently more likely to remain silent than they are to find an alternative whistleblowing avenue - even an authorised internal one. Moreover, when employees do report externally, this is usually after they have already reported internally. Given the lower organisational loyalty and trust recorded by external whistleblowers and further results on outcomes set out in Chapter 5, it is likely that the decision to use an external, authorised reporting path is often made after problems arise with the organisation's handling of the matter, rather than being identified as an option to start with.

These results increase the need for organisations to place greater effort on training and equipping their managers to handle disclosures appropriately, but also on educating employees about the availability of different reporting avenues. They also increase the need for closer coordination between line and integrity agencies to ensure disclosures are managed in the most appropriate way as early as possible, including by direct reference to external agencies. The alternative is to continue to assume that whistleblowers themselves will know how to make their disclosures to the most appropriate place and to wait for whistleblower dissatisfaction to become the trigger for further external scrutiny, potentially after it is already too late.

\section{ENDNOTES}

1 Another possibility is question bias, based on the response order for the relevant items in the questionnaires, since the first two responses are 'my supervisor' and 'another manager more senior than

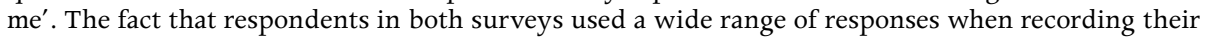
overall reporting experiences (see the second columns in Tables 4.1 and 4.2), however, suggests that question bias was not a factor.

2 Employee survey: Q2, based on Graham (1989) and Moorman and Blakely (1995). Respondents used a five-point Likert scale ranging from 1 ('strongly disagree') to 5 ('strongly agree'), in which a higher score indicated higher OCB. Although Moorman and Blakely (1995) used a seven-point scale, a five-point scale was used here to maintain consistency across the survey. Moorman and Blakely (1995) obtained the following alpha reliabilities: 0.61 ('personal industry'), 0.74 ('interpersonal helping'), 0.76 ('individual initiative') and 0.86 ('loyal boosterism').

3 Demographic variables in the analyses: it was necessary to perform analyses to determine whether any of the demographic variables impacted significantly on the variables of interest. Those demographic variables that were associated significantly with any of the OCB dimensions - trust, the whistleblowing-propensity factors or internal reporting or external reporting variables (as tested by correlations and ANOVA) - were held constant in the analyses. To be conservative, significance was tested at an alpha level of 0.10 . It was important to ensure that any effects found were the result of the hypothesised relationship being tested, rather than other confounding factors. The highest level of education, gender, age, tenure in the public sector, tenure in the organisation, role within the organisation, annual salary range, employment status, union membership, audit/fraud risk management/corruption prevention/investigation as part of job duties, size of immediate work section and work location were found to be associated with all or some of the variables of interest at an alpha 
level of 0.10, and these were therefore held constant as required in the various analyses, dependent on which variables were entered in the model.

Statistical techniques: all surveys were used as there were no out-of-range responses or significant amounts of missing data. The small level of missing data did not adversely affect the analyses as it was accounted for by calculating the scales with a requirement of at least an 80 per cent response rate for each. The hypotheses were tested using the following statistical techniques: correlations and comparison of correlations, ANOVA at an alpha level of 0.05.

4 Respondents used a five-point Likert scale ranging from 1 ('strongly disagree') to 5 ('strongly agree'), in which a higher score indicated a higher likelihood of reporting either internally or externally.

5 Statistics for this and other analyses are as follows:

\begin{tabular}{|l|l|}
\hline Hypotheses & Statistics \\
\hline 1 & $\begin{array}{l}\text { Interpersonal helping: } \mathrm{t}(7 \text { 376) }=11.91, \mathrm{p}<0.001 \text { Individual initiative: } \mathrm{t}(7 \mathrm{376})= \\
\text { 12.41, }<<0.001 \text { Personal industry: } \mathrm{t}(7 \mathrm{376})=7.30, \mathrm{p}<0.001 \text { Loyal boosterism: } \mathrm{t}(7 \\
376)=16.70, \mathrm{p}<0.001\end{array}$ \\
\hline 3 & $\begin{array}{l}\text { Interpersonal helping: } \mathrm{F}(12046)=7.85, \mathrm{p}<0.01 \text { Individual initiative: } \mathrm{F}(12045)= \\
6.64, \mathrm{p}<0.05 \text { Loyal boosterism: } \mathrm{F}(12029)=15.02, \mathrm{p}<0.001\end{array}$ \\
\hline 4 & $\begin{array}{l}\text { Interpersonal helping: } \mathrm{F}(11408)=5.50, \mathrm{p}<0.05 \text { Individual initiative: } \mathrm{F}(11407)= \\
8.12, \mathrm{p}<0.01 \text { Loyal boosterism: } \mathrm{F}(11394)=15.04, \mathrm{p}<0.001\end{array}$ \\
\hline 5 & $\mathrm{t}(340)=2.87, \mathrm{p}<0.01$ \\
\hline 6 & $\mathrm{~F}(12042)=125.12, \mathrm{p}<0.01$ \\
\hline 7 & $\mathrm{~F}(11405)=112.20, \mathrm{p}<0.001$ \\
\hline
\end{tabular}

